\title{
Economical Feedback of Increasing Fuel Enrichment on Electricity Cost for VVER-1000
}

\author{
Dwiddar,M. S ${ }^{1}$., Badawi, A . A., Abou-Gabal, H. H¹. El-Osery, I. A. ${ }^{2}$, Badawy, M. R², \\ ${ }^{1}$ Faculty of Engineering, Alexandria University \\ Alexandria, Egypt., \\ ${ }^{2}$ Nuclear Power Plants Authority, Nasr City, Cairo, Egypt.
}

\begin{abstract}
A methodology of evaluating the economics of the front-end nuclear fuel cycle with a price change sensitivity analysis for a VVER-1000 reactor core as a case study is presented. The effect of increasing the fuel enrichment and its corresponding reactor cycle length on the energy cost is investigated. The enrichment component was found to represent the highly expenses dynamic component affecting the economics of the front-end fuel cycle. Nevertheless, the increase of the fuel enrichment will increase the reactor cycle length, which will have a positive feedback on the electricity generation cost (cent/KWh). A long reactor operation time with a cheaper energy cost set the nuclear energy as a competitive alternative when compared with other energy sources.
\end{abstract}

Keywords - Front end fuel cycle economics; electricity cost; VVER-1000.

\section{NOMENCLATURE -}

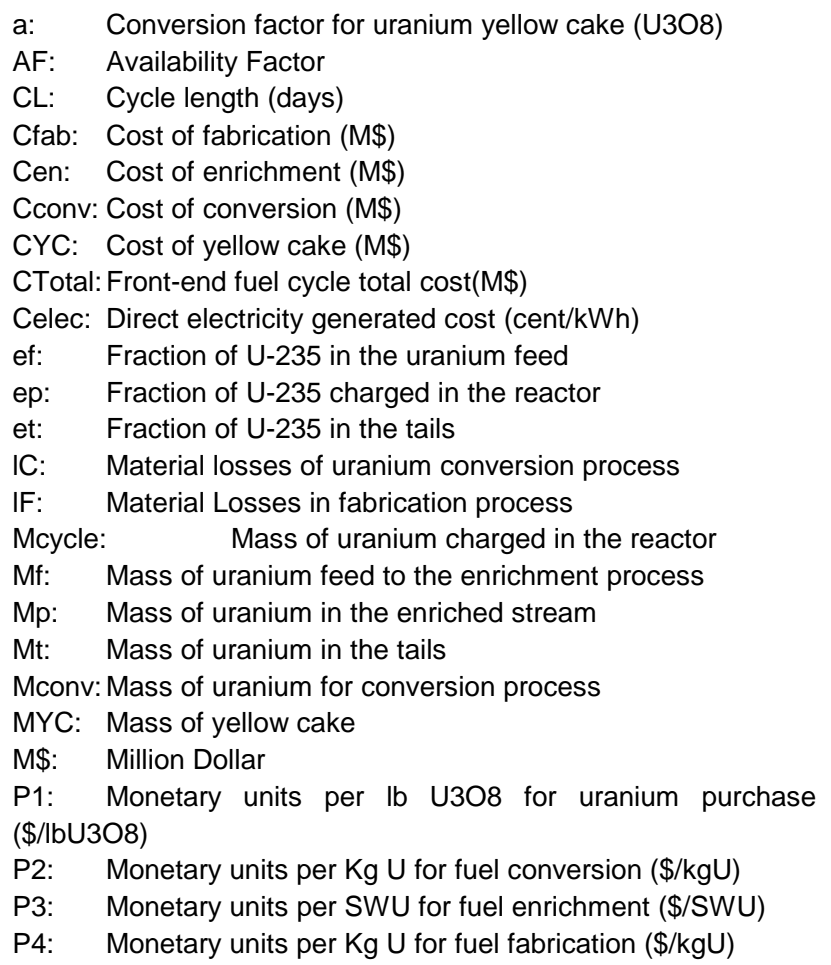

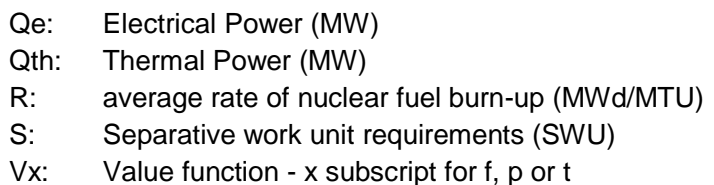

\section{INTRODUCTION}

The economics of nuclear fuel cycle for nuclear power plants depends generally on two main issues, the nuclear fuel cycle components and the reactor core cycle length. The nuclear fuel cycle can be divided into three stages: front-end, at-reactor and back-end. These, in turn, can be sub-divided into more specific components [1].To identify the generating electricity costs from a typical nuclear power plant, the economics of fuel cycle must be clear. Actually, most countries study the economics and properties for the first two stages of nuclear fuel cycle; front-end and reactor operation time as there is no clear long term strategy made for the back-end part till now. Moreover the large dependency on storage of spent fuels in reactor site increases this foggy vision of the nuclear fuel cycle back-end strategy.

Over the past decade the discharge irradiation level (burn-up) of both Pressurized Water Reactor (PWR) and Boiling Water Reactor (BWR) fuels has increased steadily. This development is mainly attributable to the increased economic benefit that is associated with higher fuel burn-up.

This benefit comes from the reduced throughput of fuel that results from higher burn-up [2]. In this paper, we calculate the generating electricity costs for PWR being the most prevalent reactor type in the world as it represents 274 of the world's 436 reactors now operating [3]. The calculations are performed considering a typical VVER-1000 reactor [4] as a case study. 


\section{VVER-1000 GENERATING ELECTRICITY COST}

\section{A. Front-end Fuel Cycle Cost}

The front-end component is composed of uranium purchase, conversion of yellow cake into uranium hexafluoride (UF6), enrichment (isotope separation process to rise the content of fissile materials, U235, in the fuel) and uranium oxide fuel fabrication into assemblies. Based on a direct cost analysis for the front-end fuel cycle components, the amount and price of each component can be defined [1]. Table 1 gives the magnitude of each front-end component unit price [5]. Most fuel contracts are made based on long term contracts not on spot prices so the front-end components unit prices are taken as average values for the past three years.

Table 1. FRONT-END COMPONENTS UNIT PRICES (5)

\begin{tabular}{|c|c|}
\hline Component & Price $^{*}$ \\
\hline Uranium purchase (P1) & $\$ 45 / \mathrm{lbU} 3 \mathrm{O} 8$ \\
\hline Conversion (P2) & $\$ 8 / \mathrm{KgU}$ \\
\hline Enrichment (P3) & $\$ 120 / \mathrm{SWU}^{* *}$ \\
\hline Fabrication (P4) & $\$ 260 / \mathrm{KgU}$ \\
\hline
\end{tabular}

* average prices over the past 3 years.

** SWU: Separative Work Unit

Based on the VVER-1000 reactor core configuration and the plant design parameters [4], the amount of required fuel charged to the reactor each cycle can be calculated using (1) [6].

$\mathrm{M}_{\text {cycle }}=\frac{\mathrm{Q}_{\mathrm{th}} \cdot \mathrm{CL}}{\mathrm{R}}$

Within the context of Dwiddar, M.S., et al.'s previous work on the VVER-1000 reactor core and its improvements to achieve the new design of VVER1200reactor core, MCNP-X code was used to calculate the core cycle length and the burn up [7].The VVER-1000 validated model showed that for a $3000 \mathrm{MW}$ th, the average value of fuel burn-up is $11800 \mathrm{MWd} / \mathrm{MTU}$ and the core cycle length is 300 days [7].

Using (1) the amount of required fuel is 76.2 tons of uranium. The value of burn-up is assumed to be an average value for the whole core for one cycle length time. The reactor core consists of three batches and only one batch will be replaced each cycle. Therefore, the output of (1) will be divided by 3 as it will be $76.2 / 3=25.4$ tons of uranium, which represents the amount of required fuel for each cycle length. Going backwards through the front-end components, this amount of uranium represents the output of fabrication stage.

The mass of uranium, Mp, required for the fabrication is slightly more than the mass of UO2in the core, Mcycle, due to fabrication losses. To calculate the amount needed for the fabrication stage, the occurring losses must be considered. The loss factor of fabrication stage is $1.0 \%$ [1]. Thus applying (2) [1], a value of 25.65 tons is obtained for $\mathrm{Mp}$.

$\mathrm{M}_{\mathrm{p}}=\mathrm{M}_{\mathrm{cycle}} \cdot\left(1+\mathrm{l}_{\mathrm{F}}\right)$

Using (3) [1] the cost of this amount is calculated based on the price value in table 1 , and is found to be equal to $6.669 \mathrm{M} \$$.

$\mathrm{C}_{\mathrm{Fab}}=\mathrm{M}_{\mathrm{p}} \cdot \mathrm{P}_{4}$

Moving to the enrichment stage, to calculate the amount of uranium required for the enrichment process, both the enriched and depleted assays (ep $\&$ et) must be well known. The fuel enrichment batch charged for the VVER-1000 case study is 3.3\% which will be refueled to the reactor core each cycle so the enriched assay output for the enrichment process is $3.3 \%$. The depleted assay is assumed to be $0.25 \%$ which is the prevalent value for the enrichment process in Russia. According to (4) [1] the feed material for the enrichment process is calculated and a value of $169701.73 \mathrm{Kg} \mathrm{U}$ is obtained. Equation (5) [1] gives the amount of depleted uranium from this specific enrichment process and it is equal to $144051.73 \mathrm{Kg} \mathrm{U}$.

$M_{f}=\left[\frac{e_{p}-e_{t}}{e_{f}-e_{t}}\right] \cdot M_{p}$

$M_{t}=M_{f}-M_{p}$

Since the price of enrichment services is expressed per separative work unit (SWU), the quantity of SWUs necessary to obtain the enriched uranium quantity (Mp) at the required enrichment level (3.3\%) must be calculated. This quantity can be estimated depending on the 'value' of a mixture (V) which is 
estimated on equation (6) as a function of the U235 content. Equation (7) [1] gives the SWU required for this specific enrichment process. According to (7), the separative work need for this process is equal to 113289 SWU.

$\mathrm{V}_{\mathrm{x}}=\left(2 \cdot \mathrm{e}_{\mathrm{x}}-1\right) \cdot \ln \left[\frac{\mathrm{e}_{\mathrm{x}}}{1-\mathrm{e}_{\mathrm{x}}}\right]$

$S=M_{p} \cdot V_{p}+M_{t} \cdot V_{t}-M_{f} \cdot V_{f}$

Thus, the cost of enrichment is calculated using (8) [1] and is found to be equal to $13.7 \mathrm{M} \$$.

$\mathrm{C}_{\mathrm{en}}=\mathrm{S} \cdot \mathrm{P}_{3} \cdot\left(1+\mathrm{l}_{\mathrm{F}}\right)$

Moving to the conversion stage, the amount of uranium required is calculated using (9) [1]. This amount is equal to $170550.24 \mathrm{Kg} \mathrm{U}$ considering the loss factor of conversion stage to be $0.5 \%$ [1]. According to the calculated uranium amount and using (10) [1] the cost of conversion process is calculated to be $1.364 \mathrm{M} \$$.

$$
\begin{aligned}
& M_{\text {conv }}=M_{\mathrm{f}} \cdot\left(1+\mathrm{l}_{\mathrm{C}}\right) \\
& \mathrm{C}_{\mathrm{conv}}=\mathrm{M}_{\mathrm{conv}} \cdot \mathrm{P}_{2}
\end{aligned}
$$

Finally, the amount and cost of yellow cake to be purchased for starting the nuclear fuel cycle processes have to be calculated. Equations (11) and (12) [1] give the amount and the cost respectively. The amount of yellow cake is equal to $443430.63 \mathrm{lb}$ and the cost is $19.95 \mathrm{M} \$$.

$\mathrm{M}_{\mathrm{YC}}=\mathrm{M}_{\mathrm{conv}} \cdot \mathrm{a}$

$\mathrm{C}_{\mathrm{YC}}=\mathrm{M}_{\mathrm{YC}} \cdot \mathrm{P}_{1}$

Fig. 1 summarizes the actual annual front-end fuel cycle requirements for the VVER-1000 case study. The total front-end fuel cost is the sum of all its components cost. Equation (13) [1] gives the total cost which is equal to $41.69 \mathrm{M} \$$.

$\mathrm{C}_{\text {Total }}=\mathrm{C}_{\mathrm{YC}}+\mathrm{C}_{\mathrm{conv}}+\mathrm{C}_{\mathrm{en}}+\mathrm{C}_{\mathrm{Fab}}$

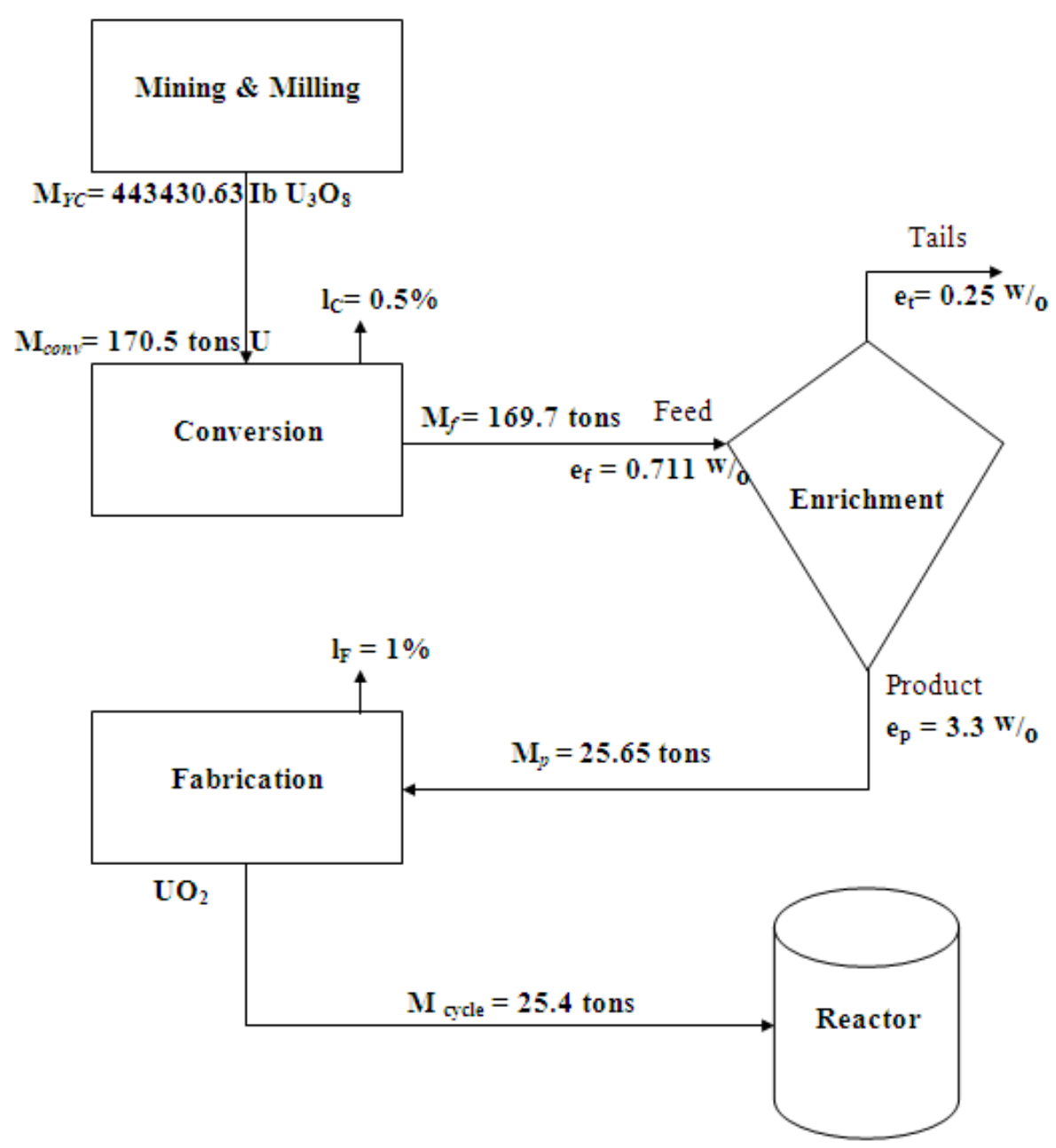

Fig .1. Annual VVER-1000 front-end fuel cycle requirements 
From the calculated front-end fuel cycle total cost and considering a plant's availability factor of $82 \%,(14)$ estimates the direct fuel cost for the unit electricity generation to be 0.7047 cent $/ \mathrm{kWh}$. This value represents the direct electricity generation cost according to the front-end fuel cycle economics.

$\mathrm{C}_{\mathrm{elec}}=\frac{\mathrm{C}_{\text {Total }}}{\mathrm{Q}_{\mathrm{e}} \cdot \mathrm{CL} \cdot \mathrm{AF} \cdot 24} \times \frac{100(\mathrm{Cent} / \$)}{1000(\mathrm{kWh} / \mathrm{MWh})}$

\section{B. Price Sensitivity Analysis}

A sensitivity analysis has been carried out with respect to the unit prices for the front-end fuel cycle components. The sensitivity range for front-end service prices generally reflects the upper and lower bound values seen from the extrapolation of component spot prices in international market [1]. The values used for the sensitivity analysis are shown in table 2.

Table 2. SENSITIVITY RANGE FOR THE FRONT-END COMPONENT UNIT PRICES

\begin{tabular}{|c|c|}
\hline Component & Price sensitivity range* $^{*}$ \\
\hline Uranium purchase & $22.5-90 \$ / \mathrm{lb} \mathrm{U}$ \\
\hline Conversion & $3.75-15 \$ / \mathrm{Kg} \mathrm{U}$ \\
\hline Enrichment & $\$ 60-240 \$ / \mathrm{SWU}$ \\
\hline Fabrication & $130-520 \$ / \mathrm{Kg} \mathrm{U}$ \\
\hline
\end{tabular}

Fig. 2 gives the results of the front end fuel cycle components prices sensitivity analysis applied on the direct electricity cost. It is clear that although the uranium purchase is the highly significant component, enrichment cost is the most effective because it is the dynamic process that affects all other components.
So it may be deduced that the enrichment cost forms a significant component of the front-end fuel cycle costs.

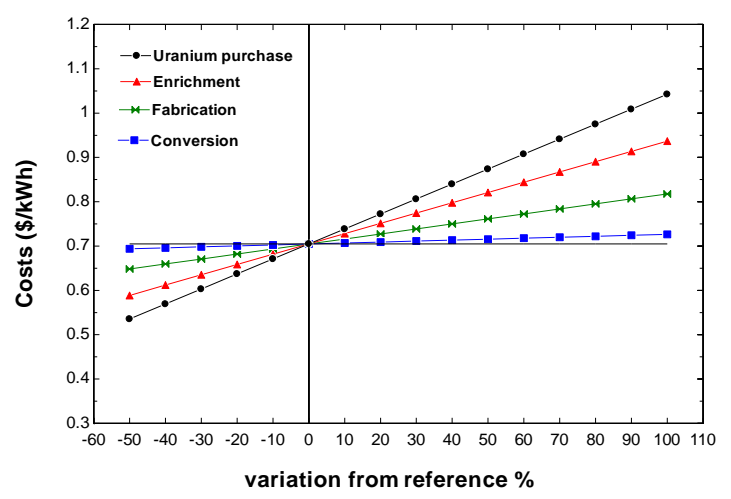

Fig .2. Effect of front end fuel cycle components price change on electricity direct costs

\section{Effects of Increasing Enrichment and Core Cycle Length}

For increasing the reactor core cycle length, it is required to increase the fissile material content in the reactor core. This will affect the economics of fuel cycle components. From international practice, the maximum allowable enrichment for PWRs is $5 \%$. For saving the design basis parameters for the VVER1000 case study, the minimum enrichment batch of VVER-1000 model is increased by a step of 0.1 . The enrichments of the other batches are also increased keeping the same ratio of enrichment between the three batches as in the reference case. According to this assumption, the maximum enrichment calculated is $4.95 \%$. [7] Table 3 gives all probable improvements of fuel batches enrichment within the maximum allowable value with the corresponding reactor cycle length and core average burn up. The reactor cycle length and the core average burn up are out data from the MCNP-X code [7].

Table 3. CHANGES CONSIDERED IN THE ENRICHMENT OF THE FUEL BATCHES [7]

\begin{tabular}{|c|c|c|c|c|c|}
\hline \multirow{2}{*}{ Cases } & \multicolumn{3}{|c|}{ Enrichment of Fuel Batches } & \multirow{2}{*}{ Cycle length (days) } & $\begin{array}{c}\text { Average burnup (MWd/ } \\
\text { MTU) }\end{array}$ \\
\cline { 2 - 4 } & Batch 1 & Batch 2 & Batch3 & 300 & 11800 \\
\hline A (Ref. Case) & 2 & 3 & 3.3 & 336 & 13213 \\
\hline B & 2.1 & 3.15 & 3.465 & 372 & 14626 \\
\hline C & 2.2 & 3.3 & 3.63 & 408 & 16039 \\
\hline D & 2.3 & 3.45 & 3.795 & 444 & 17452 \\
\hline E & 2.4 & 3.6 & 3.96 & 480 & 18865 \\
\hline F & 2.5 & 3.75 & 4.125 & 516 & 20278 \\
\hline G & 2.6 & 3.9 & 4.29 & 552 & 21691 \\
\hline H & 2.7 & 4.05 & 4.455 & 588 & 23104 \\
\hline I & 2.8 & 4.2 & 4.62 & 624 & 24517 \\
\hline J & 2.9 & 4.35 & 4.785 & 660 & 25930 \\
\hline
\end{tabular}


According to the output data given in table 3, Fig. 3 shows that the fuel burn-up is directly proportional to the core cycle length.

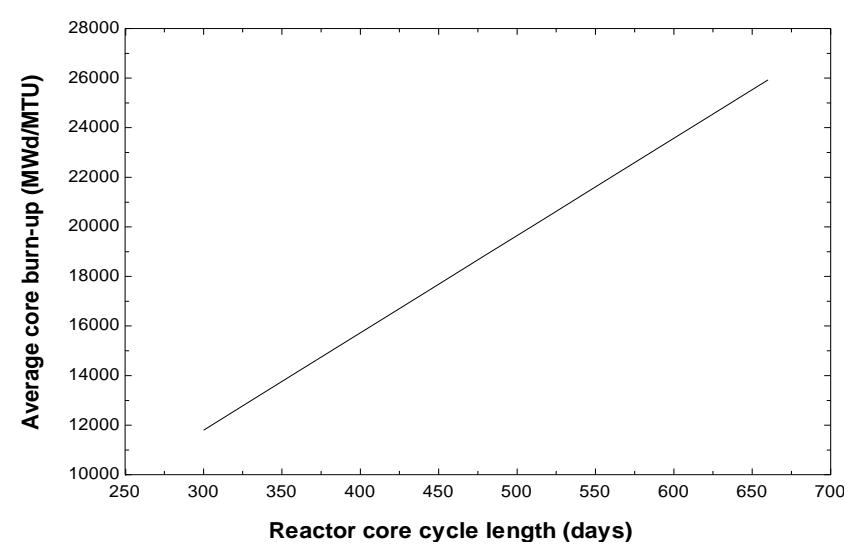

Fig .3. Relation between core cycle length and fuel burn-up

Similarly to case A already considered in section A, (1) to (14) were used to calculate the front end fuel cycle economics and its effect on the electricity generation cost for the other cases.

Calculating the fuel mass required each cycle for the different cases results in a constant value as shown in Fig. 4. This can be explained by the proportionality relation obtained between the core cycle length and the fuel burn-up. As (2) and (3) do not depend on the enrichment percentage, this constant value of fuel mass required each cycle will be reflected in a constant value for both the required mass for the fabrication stage and its cost, namely 25.65 tons and $6.669 \mathrm{M} \$$ respectively.

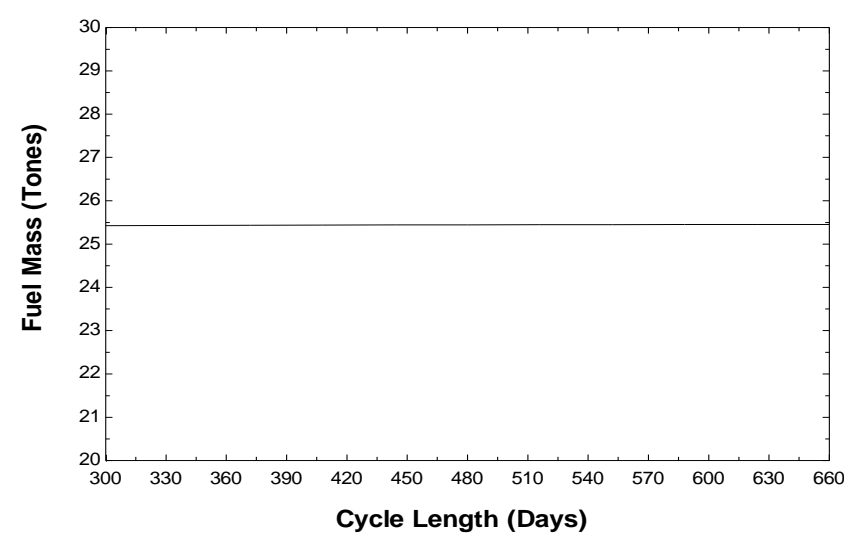

Fig .4 Fuel mass required each cycle for the different cases in table 3

However as fuel enrichment increases, the feed material will increase. Consequently the enrichment cost will increase due to the need for more separative work units as seen in Fig. 5. Fig. 6 shows that the cost of enrichment process is directly proportional to the mass of uranium feed.

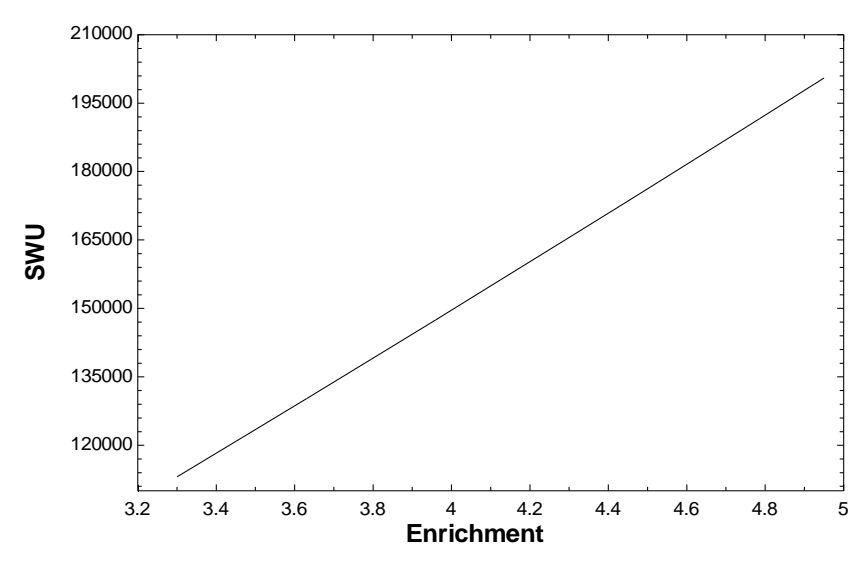

Fig .5 Amount of required SWU for different fuel enrichments

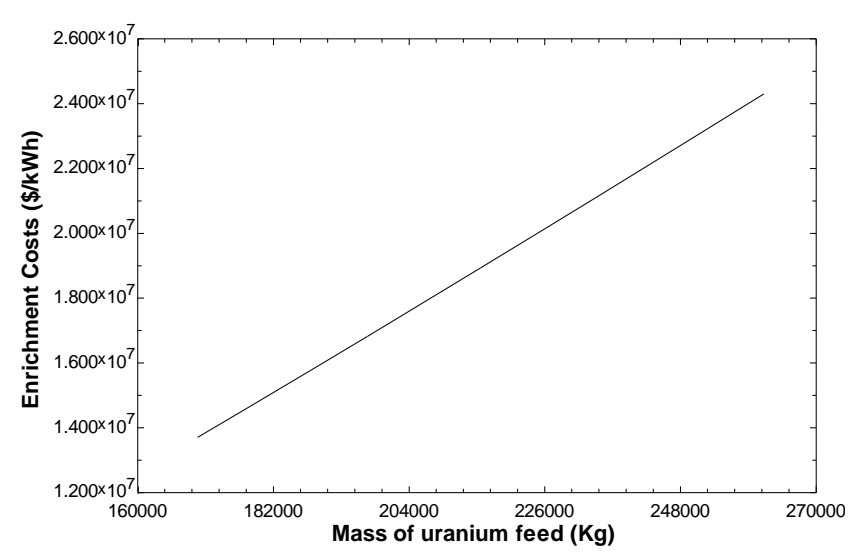

Fig .6 Enrichment process cost versus the mass of uranium feed

The increase in the uranium feed to the enrichment process leads to the need for more uranium for both the conversion and the uranium purchase components resulting in an increase in their costs as illustrated in Figs. 7 and 8.

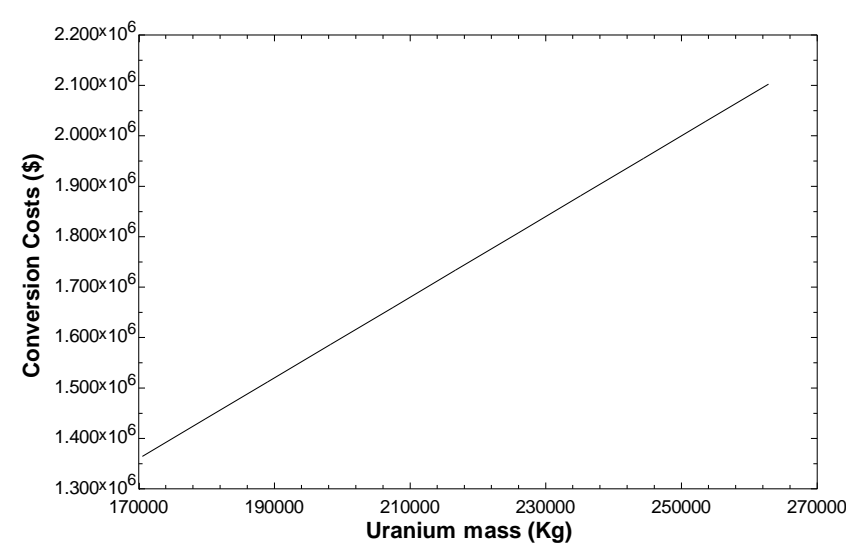

Fig .7 Conversion costs versus the mass of uranium 


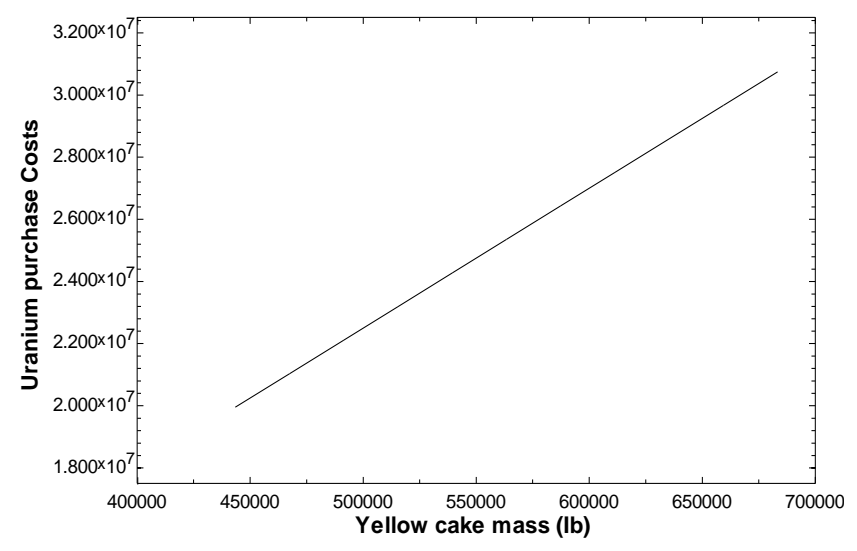

Fig .8 Uranium purchase costs versus the mass of uranium

As a consequence of the increase in the costs of the uranium enrichment, the conversion and the uranium purchase components, the total cost of the front end fuel cycle will increase. But since the increase in the uranium enrichment will lead to longer reactor core cycle length due to the higher fuel burn-up, the resulting electricity cost decreases as shown in Fig. 9.

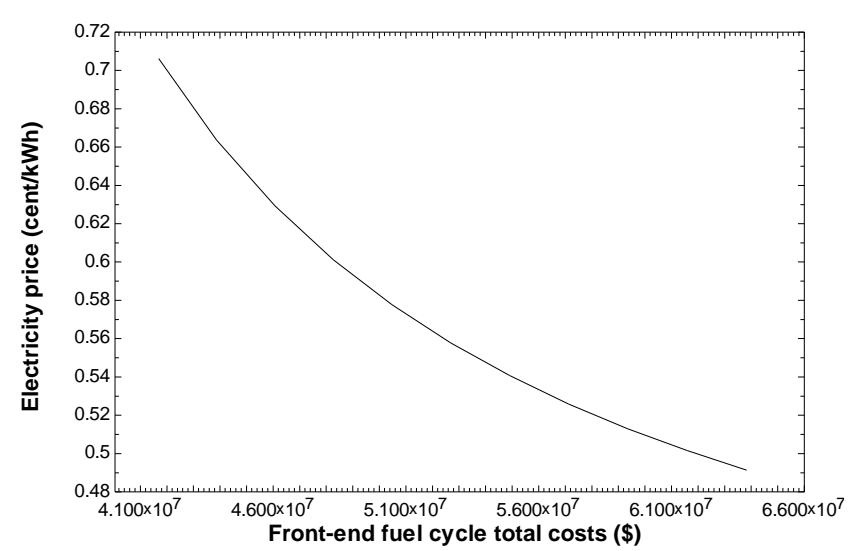

Fig .9 Direct electricity cost versus total front-end cost

\section{CONCLUSION}

The effect of increasing the nuclear fuel enrichment on the electricity cost has been considered. A typical VVER-1000 reactor has been selected as the case study. The fuel enrichment has been increased up to $5 \%$ which is the maximum allowable value for PWRs. Excluding the fabrication component, increasing fuel enrichment was found to increase the uranium masses needed for all the front-end components and consequently their costs.

A sensitivity analysis was performed with respect to the unit prices for the front-end fuel cycle components and their effects on the electricity direct cost. It was noticed that although the uranium purchase is the most effective component, the uranium enrichment still has the highly priority effect due to its dynamic properties and its consequences on the other frontend fuel cycle components. Although increasing the fuel enrichment resulted in a higher total cost of the front end fuel cycle, it was found to extend the reactor core cycle allowing the reactor to operate for more than 12 months. This fact results in a decrease in the electricity generation cost.

Therefore, increasing the nuclear fuel enrichment within the limit allowable internationally for the PWRs will have a positive economic feedback leading to a cheaper electricity cost. This makes the nuclear energy a strong competitor to the other energy sources

\section{REFERENCES}

[1] Nuclear Energy Agency, The economical on nuclear fuel cycle (1994), Organization for economic co-operation and development, Paris, France.

[2] Christopher S. (June 1998) Economic and Fuel Performance Analysis of Extended Operating Cycles in Existing Light Water Reactors (LWRs), Handwork, Massachusetts Institute of Technology,

[3] PRIS, IAEA,( August 2014) Power Reactor Information System. www.iaea.org/PRIS/WorldStatistics/Operational ReactorByTupe.aspx

[4] IAEA, (November 1995) In-core fuel management code package validation for WWERs. IAEA-TECDOC-847.

[5] The Ux Consulting Company (August 2014). www.uxc.com/review/UxCProces.aspx

[6] Cacuci, D. G. (2010) Handbook of Nuclear Engineering, Institute for Nuclear Technology and Reactor Safety. Karlsruherlnstitut fur Technologie, Germany.

[7] Dwiddar, M. S. (May 2014) From VVER-1000 to VVER-1200: investigation of the effect of the changes in core. The third international conference on physics and technology of reactors and applications, Tetuan, Morocco. 